\section{Quinquefoliate Strawberry}

IT may interest botanical readers to know that we have here a variety of strawberry many petioles of which bear five leaflets. This kind of leaf is aiso transmitted to its offspring when propagated by runners, and I think it may be possible to raise from seed progeny the whole of whose petioles will bear five leaflets. It is an excellent variety in every respect; the fruit is symmetrical, and of rich flavour. When we consider that Duchesne's strawberry, Fragaria monophylla (described by Mr. Dyer in NATURE, vol. xxix. p. 215), was unifoliate, and that ordinary strawberries are trifoliate, this variety certainly is unique, and suggests still further possibilities of development in the genus Fragaria.

Driffield, April 16

SOME OF THE METEOROLOGICAL RESULTS OF THE TOTAL SOLAR ECLIPSE OF MAY 6, I $883^{1}$

$\mathrm{T}$ the expedition sent by the United States Govern1 ment to Caroline Island $\left(9^{\circ} 59^{\prime} 45^{\prime \prime} \mathrm{S}\right.$. lat. and $150^{\circ} 14^{\prime} 24^{\prime \prime} \mathrm{W}$. long.) to observe the total eclipse of May 6,1883 , provision was made for taking a series of meteorological observations on the occasion. The observations, which were of an elaborate description, are fully detailed and summarised by $\mathrm{Mr}$. Upton in the Report, and they present results of exceptional interest.

During the eclipse the velocity of the wind remained practically constant, and, so far as the readings of the radiation thermometers showed, the heat received by the earth was almost nil. The temperature of the air, which, previous to the eclipse, had been $84^{\circ} 5$, fell to $81^{\circ} 4$, or $0^{\circ} .1$ lower than it had been at 7 a.m., and $0^{\circ} .6$ lower than it was at 9 p.m. The amount of the temperature depression due to the withdrawal of the sun's heat was $3^{\circ} \cdot 9$; and, corresponding with this lowering of the temperature, the relative humidity increased 5 per cent. during the eclipse.

The main interest of the observations, however, centres in the influence of the eclipse on the diumal barometric curve. The diurnal march of the atmospheric pressure in these regions may well be classed among the most regularly recurring phenomena of terrestrial physics. From hourly observations made from April 25 to May 5 the mean at 10 a.m. was $29^{\circ} 957$ inches, and at 2 p.m. $29^{\circ} 84$ inches, the barometer thus falling in these four hours 0.113 inch. Between these hours, on May 6, the eclipse occurred, the total phase of the eclipse being from II. 32 to $11^{\prime} 37$ a.m. On that day the barometric curve presented a form wholly different from what is daily observed in these regions. From $10^{\circ} 30$ to $1 I^{2} 25$ a.m. the barometer fell with a greater rapidity than the normal rate of fall, being at II.20 a.m. 0.016 inch lower than the normal at that hour. Immediately thereafter a rapid and abnormal rise set in, the usual fall being arrested and replaced by an actual rise, so that while pressure at ir.20 a.m. was 29.927 inches, at I I.50 a.m. it was $29^{\circ} 940$ inches. At r2.10 p.m. it was o.o 9 inch above the normal for that hour. Since the barometer was 0.016 inch lower than the normal at II.20 a.m., and 0.019 inch higher at 12.10 p.m., it follows that the disturbance from the normal values during these fifty minutes occasioned by the eclipse amounted to 0.035 inch, being equal to nearly a third of the whole diurnal oscillation from the morning maximum to the afternoon minimum.

The time and manner of this abnormality is of special significance, inasmuch as it indicates a more rapid fall than the average during the first partial phase, when the sun's heat began to be cut off, and a rise above the average wholly exceptional after the close of the total phase, the maximum rise being delayed thirty-three

I Report of observations made on the expedition to Caroline Island to observe the total solar eclipse of May 6, r883, by Winslow Upton. (Washington, 1884 .)

minutes after the period of totality. An eclipse differs essentially from all other influences affecting the atmosphere, in that it cuts off the sun's heat from a restricted section of the earth's atmosphere extending from the surface to the extreme limits of the atmosphere, while from the air surrounding the shaded region the sun's heat is not cut off. Now, the observations showed that the first effect of the cutting off of the sun's rays and consequent reduction of the temperature, which no doubt extended through the whole height of the atmosphere, was to lower the pressure below the normal. This diminished tension was simply the direct result of the lowering of the temperature of the air over the region where the barometric observations were made.

Following this diminution of the pressure, an inflow of air towards the retreating path of the shadow set in, and pressure quickly rose above the normal of the hour, and as the sun's rays now heated the air with this excess thus temporarily accumulated over Caroline Island, pressure rose still further, till at thirty-three minutes after the close of the total phase it was o.org inch above the normal. Thereafter pressure fell with a corresponding rapidity during the next twenty minutes, at the close of which time it stood at the normal. The whole phases of the disturbance in the diurnal march of the pressure caused by the eclipse occupied two hours ending with $12.30 \mathrm{p} . \mathrm{m}$. It is from their bearings on the theory of the diurnal oscillations of the barometer that Mr. Upton's observations must be regarded as of the highest importance (see "Encyclopædia Britannica," Meteorology, pp. I 22 and 123).

Pointed attention is given in the report to the observations of the wind, which showed that, though the island is situated in the region usually included in the south-east trades, yet the direction of the wind was almost always noted as east or north-east, and was at no time observed to be from any other quarter than between north and east. Not a single observation during the time the expedition was on the island gave a direction south of east. The Challenger in this part of its cruise, during September, 1875 , noted the same directions of the wind, and during the cruise to southward the north-east trades were not left till lat $13^{\circ} \mathrm{S}$. was reached.

During the voyage from Callao, the Hartford sailed day after day in the region of the south-east trades, upon almost the same parallel of latitude, and with but few changes in the position of the sails, no steam being used. Since the conditions were so constant during the twentytwo days in which the vessel sailed in lat $11^{\circ} 5^{\prime} \mathrm{S}$. from long. $79^{\circ}$ to $137^{\circ} \mathrm{W}$, a tabulation of the hourly speed of the vessel day by day has been made from the ship's log. The mean values show a distinct increase in the evening, and a corresponding decrease in the morning, the maximum, 6.8 miles per hour, occurring at ro p.m., and the minimum, 5.9 miles, at Io a.m. With reference to the result, Mr. Upton remarks that, "It seems fair to attribute this to a diurnal variation in the wind's velocity. There is quite an unexpected regularity in the progression when we consider the approximate nature of the method. If not attributable to diurnal change in the wind itself, it yet indicates a diurnal change in the effect of the wind upon the sails, and is therefore of interest."

\section{SIR WILLIAM THOMSON ON MOLECULAR DYNAMICS ${ }^{2}$}

III.

BEFORE proceeding with new parts of this subject, I wish to say a few words about "fiddling while Rome is burning." Sir William Thomson writes to me that the expression was used while discussing some mathematical triviality, and he wishes to be relieved of the imputation

\footnotetext{
I Continued from p. 5ro.
} 
of speaking disrespectfully of anomalous dispersion, which he says is quite as important as double refraction. I grant this, but my interpretation of his language when I heard the lecture was that so many possible ways had been shown of cxplaining anomalous dispersion that it was mere child's play (or fiddlc-playing) to discuss it while the burning question of double refraction awaited explanation, upon which question seems to depend the whole safety of the wave-theory of light, that theory being in imminent danger of destruction therefrom.

I shall now give a brief account of the gyrostatic molecules, crucle and improved. The crude one is a fly-wheel inside a massless shell. Here there is no gyrostatic action opposing a motion of translation, but only opposing a motion of rotation. This is the molecule which was stated to give the wrong kind of variation of magneto-optic rotation with variation of wave-length. The improved gyrostatic molecule (p. 320) consists of two fly-wheels on one axis. But the axis is cut in two in the middle between them, and the parts fitted together by a ball and cylinder joint. The other ends of the half axes are supported in ball-and-socket joints in the massless shell. So far as rotation of the shell is concerned, this acts like one gyrostat, the axis always remaining in one line. But if the shell be frictionless, the ether can only give translational movement to it, and the double gyrostat produces a gyrostatic effect when the molecule is accelerated in any dircction except along the axis.

The special function of this molecule is to explain magneto-optic rotation of the plane of polarisation. The axis of the molecule is supposed to be the direction of the lines of force. It is required to be proved that, gyrostatic molecules being imbedded in the ether with their axes parallel and their directions of rotation the same, the velocity of propagation of a circular disturbance going with the gyrostat is greater than that of a circular disturbance in the opposite direction. With a steady propagation of circularly polarised light, the gyrostats will clearly execute a precessional motion. The theory of this motion is examincd after the manner of Thomson and Tait's "Natural Philosophy" for a ray along the axes, and the gyrostatic effect is found to be equivalent to altering the effective density of the molecule, and so altering the velocity of propagation. Thus if $z^{\prime}$ and $v^{\prime}$ are the velocities of propagation along the axis of rays polarised circularly in the two directions, it comes out that approximately

$$
\frac{v^{\prime}}{v^{\prime}}=\mathrm{I}+h^{\omega}, \frac{\omega}{\gamma}
$$

where $h$ is a constant depending on the form of the gyrostats, $\omega$ is the angular velocity of the precessional rotation of the gyrostats, and $\gamma$ is the velocity of rotalion of the gyrostats. This is a totally different law to the action of the crude gyrostatic molecule, and is in accordance with experiment.

If now we have improwed gyrostatic molccules imbedded in the ether, their minute rotations will affect the velocity of propagation in the manner of crude molecules, but their translations will affect the velocity in the manuer now elucidated. But observe that by diminishing the size of the molectiles the influence of the rotational motion diminishes, but the influence of the translational motion remains the same (on the assumption that the angular gyrostatic velocity is kept the same and the ratio of mass of gyrostats to mass of molecule remains the same). Hence, if we have small enough molecules, the law which agrees with experiment alone holds. This is a very satisfactory state of affairs, and I believe it is the first time that Sir William Thomson's hint about this phenomenon, so long ago thrown out, has been developed.

There is still so much matter in the lectures that I have not touched upon that I am in some difficulty as to what to omit. But I certainly should like to transcribe nearly the whole of the last lecture. This is of course impossible, but I will claim a little space for some remarks on Rankine's beautiful but futile attempt to get over the fatal difficulty of double refraction (p.27I):-

"Suppose here a massless rigid lining of our ideal cavity in the luminiferous ether. Let there be a massive, heavy molecule inside, with fluid around it. The main thing is that this molecule, which only affects the effective inertia of the ether by adding its own mass to the moving mass of the ether, has xeolotropy of inertia. Imagine thic spherule (drawing on the board an oblate spheroid with axis vertical) moving first in a horizontal direction. The effective inertia of this sheath will be altercd if it moves to and fro in a vertical direction, there being, by hypothesis, liquid between it and the ether. The density of this mass must be greater than the density of the liquid, that is all. If there is danger of its coming to the sides of the cavity, let there be springs to keep it in place, if you like, but let its connection with the lining of the cavity be in the main through fluid pressure. Then its effective inertia is different in different directions. This fluid lining seems to hit off the very thing we wanted. Now comes Rankine's want of strength. He cut around the edges of it, and, I think, rather jumped at it, and put down a wave-surface the samc as Fresnel's, and said that it came to that. But, alas! Stokes (long before Lord Rayleigh suggested it) showed that it would give a different surface from Fresnel's. Lord Rayleigh, in repeating Rankine's suggestion, showed his strength where Rankine was not so strong in mathematical powers of grappling with a difficult mathematical problem. Lord Rayleigh is a man who grapples with a difficulty and sees how much he can do with it. He puts it aside if he cannot solve it, but he never shirks it. Rankine was not a mathematician in that sense at all. Lord Rayleigh finds, not Fresnel's wave-surface, but a wavc-surface diffcring from Fresnel's by certain terms appearing in reciprocals instead of directly."

Now Stokes has shown that Huyghen's construction satisfies experiment with great accuracy, and hence Rankine's effort fails. The desperate condition of the wavetheory is shown by the words penned by Lord Rayleigh before he knew of Stokes's experiments (p. 272): "Should the verdict go against the view of the present paper, it is hard to see how any consistent theory is possible which shall embrace at once the laws of scattcring, regular reflection and double refraction."

It appears, then, that after all the labour which has been expended upon the wave-theory of light, it fails. absolutely, and, as it seems, hopelessly, in two points of primary importance. One is the extinction of the ray polarised by reflection; the other is double refraction. In other matters we have difficulties, but we can see a possible means of cscape. Here there seems to be none.

Before concluding this series of articles $J$ wish to say a little more about the manner of their delivery. It is a rare experience for students to have the opportunity of studying the workings of a great mind while grappling with a problem. This is what occurred during the three weeks of the Baltimore lectures. During the whole of this period one or two ardent students were hunting up references in the Peabody Library, \&c., and literally filled Sir William Thomson's rooms with the results of their searches, and Sir William generally read these books. He says (p. 76):- "An interminable number of books have been brought to me, and in every one of them 1 have found something very important." But at p. 98 he says :- "I got another quarter-hundredweight of books on the subject. I have not yet read them all through." In this way he often came for the first time upon rescarches bearing on the question in hand. Thus (p. 77): "I only found this morning that Lommel also goes on to double refraction of light in crystals [with imbedded molecules]. The very problem I am breaking my head 
against." Evidence is always cropping up that the author is ir the habit of going farther into a subject by original mathematical analysis than by reading up other people's work. I will give some examples. Speaking of a reference by Rankine to cubic asymmetry, he says:- "I only came across this in Rankine two or three days ago. But I remember going through the same thing myself not long ago, and I said to Stokes-I always consulted my great authority, Stokes, whenever I got a chance--'Surely there may be such a thing found to exemplify this kind of asymmetry; would it not be likely to be found in crystals of the cubic class?' Stokes -he know almost everything-instantly said : 'Oh, Sir David Brewster thought he had found it in cubic crystals, but there was an explanation that it seemed to be owing to the effect of the cleavage planes or the separation of the crystal into several crystalline laminie" (p. 158). Then again he says:- "I am ashamed to say that I never heard of anomalous dispersion until after $I$ found it lurking in the formulas. I said to myself, 'These formulas would imply that, and I never heard of it ;' and when I looked into the matter I found, to my shame, that a thing which had been known by others for eight or ten years I had not known until I found it in the dynamics" (p. I2o). Once more we find:- "I was thinking about this, three days ago, and said to myself, "There must be bright lines of reflection from bodies in which we have those molecules that can produce intense absorption. Speaking about it to Lord Rayleigh at breakfast, he informed me of this paper of Stokes's, and I looked and saw that what I had thought of was there. It was known perfectly well, but the molecule first discovered it to me. I am exceedingly interested about these things, since I am only beginning to find out what everybody else knew, such as anomalous dispersion, and tho se quasi colours, and so on " (p. 282).

The purely physical bent of the author's reasoning is well shown in speaking of Rankine's work at p. 270: "I do not think I would like to suggest that Rankine's molecular hypothesis is of very great importance. The title is of more importance than anything else in the work. Rankine was that kind of genius that his names were of enormous suggestiveness, but we cannot say that always of the substance. We cannot find a foundation for a great deal of his mathematical writings, and there is no explanation of his kind of matter. I never satisfy myself until I can make a mechanical model of a thing. If I can make a mechanical model, I can understand it. As long as I cannot make a mechanical model all the way through, I cannot understand; and that is why I cannot get ${ }^{I}$ the electromagnetic theory. I firmly believe in an electromagnetic theory of light, and that, when we understand electricity and magnetism and light, we shall see them all together as part of a whole. But I want to understand light as well as I can without introducing things that we understand even less of. That is why I take plain dynamics. I can get a model in plain dynamics, I cannot in electromagnetics. But so soon as we have rotators to take the part of magnets and something imponderable to take the part of magnetism, and realise by experiment Maxwell's beautiful ideas of electric displacements, and so on, then we shall see electricity, magnetism, and light closely united and grounded in the same system."

The model of an electromagnetic ether described by Prof. Fitzgerald on March 28 to the Physical Society, founded on Clerk Maxwell's celebrated papers in the Philosophical Magazine in 1860 and I861, goes a long way to clear away the objection raised by Sir William Thomson.

In reading these lectures, it must be remembered that they are uncorrected verbatim reports, and one is surprised at seeing that the matter is so continuous and readable. A considerable freshness is given by the con-

I These reports are generally quite verbatim, but I am sure Sir William Thomson is not responsible for this characteristic Americanism.-G. F. versational interludes and remarks, which would not perhaps have appeared in a written work. As mentioned before, Sir William spole of the pressural wave as an animal; this was very happy, as he had just before called it the bête noir of the mathematicians. He says at $\mathrm{p}$; 34 :- "I do not like the words " paradoxical phenomenon.; 'Curious phenomenon' or 'interesting phenomenon' would be better. There is no parado: in science. We may call it a dynamox, but not a paradox" At p. II5 he says:- The struggle of I8I5 (that is not the same idea as la grande guerre de 1815 ) was, who was to rule the waves, Cauchy or Poisson?"

To many it will seem, after reading these lectures containing a review of what has been done and suggestions of what might be done, that certain facts are hopelessly irreconcilable with the wave-theory of light. Sir William Thomson has certainly not shirked a single difficulty, and perhaps has even made them look more glaring than is necessary. But, if this be an error, it is on the right side.

The reporter has introduced into the volume some doggerel rhymes read by a certain student of the lectures at a farewell dimner at Baltimore given by President Gilman :-

\section{The Lament of the Tiventy-one Coefficients at parting from each other and from their E:tcem d Molecule}

An xolutropic molecule was looking at the view,

Surrounded by his coefficients twenty-one or two,

And wondering whether he could make a sky of azure blue,

With plagiotatic $a b c$ and thlipsinomic $Q$.

They looked like sand upon the shore with waves upon the sea, But the waves were all too wilful and determined to be free ; And in spite of $n$ 's rigidity they never could agree

In becoming quite subservient to thlipsinomic $P$.

Then web-like coefficients and a loaded molecule,

With a noble wiggler at their head, worked hard as Haughton's mule ;

But the waves all laughed, and said, "A wiggler, thinking he could rule

A wave, was nothing better than a sidelong, normal fool."

So the coefficients sighed, and gave a last tangential skew, And $a$ shook hands with $b$ and $c$, and $S$ and $T$ and $U$, And with a tear they parted; but they said they would be true To their much-beloved wiggler and to thlipsinomic $Q$.

Signed, $(g, f)$, a Cross Coefficient now Ansulded

The social and scientific intercourse of these three weeks at Baltimore was an experience that will be forgotten by none of the twenty-one coefficients, and they all sympathised with Sir William Thomson in his concluding remarks at p. 289 :-

"I am exceedingly sorry that our twenty-one coefficients are to be scattered, but, though scattered far and wide, I hope we will still be coefficients working together for the great cause we are all so much interested in. I would be most happy to look forward to another conference, and the one damper to that happiness is that this one is now to end, and we shall be compelled to look forward for a time. I hope only that we shall all meet again in some such way. I would say to those whose homes are on this side of the Atlantic, 'Come on the other side and I will welcome you heartily, and we may have more confercnces.' Whether we have such a conference on this side or on the other side of the Atlantic again it will be a thing to look forward to-as this is to look back uponas one of the most precious incidents I can possibly have. I suppose we must say farewell!" GEORGs: Forbes

THE SEMAPHORE AND ELECTRIC LIGHT $A T$ SHANGHAI

THE European and American community occupying the so-called foreign concessions in Shanghai has lately adopted the electric light. The illustration given 